\title{
Eating for Two: Behavioral and Environmental Correlates of Gestation Length Among Free-Ranging Baboons (Papio cynocephalus)
}

\author{
Joan B. Silk ${ }^{1}$ \\ Received February 17, 1986; revised July 1, 1986
}

Variation in environmental conditions during pregnancy and differences in
the feeding behavior of females during pregnancy were consistently associated
with variation in gestation length among free-ranging yellow baboons, Papio
cynocephalus, in Amboseli National Park, Kenya. Females whose pregnan-
cies ended during the wet season gave birth after shorter pregnancies than
females whose pregnancies ended during the dry season. When rainfall is
held constant, another source of variation in gestation length emerges.
Females that spent progressively less time feeding over the course of their
pregnancies gave birth after longer pregnancies than females that spent pro-
gressively more time feeding over the course of their pregnancies. These two
factors, which provide rough indices of maternal nutritional status, accounted
for a substantial fraction of the observed variation in gestation length among
these female baboons.

KEY WORDS: gestation; pregnancy; baboon; nutrition; fetal development.

\section{INTRODUCTION}

Variation in the length of primate pregnancies is well documented, but the factors that contribute to variation in gestation length have not been fully elucidated (Kiltie, 1982). One factor that appears to account for at least

'Department of Anthropology, University of California, Los Angeles, California 90024, and California Primate Research Center, University of California, Davis, California 95616. 
some of the variation in mammalian gestation length is maternal nutritional status during pregnancy. In several species, nutritional deprivation during pregnancy delays parturition, while in some species nutritional deprivation appears to accelerate parturition.

The effects of nutrition on gestation length have been documented most clearly in laboratory studies in which pregnant females' diets can be carefully regulated. Female rhesus macaques (Macaca mulatta) maintained after conception on high-protein diets gave birth after shorter pregnancies than females that were maintained after conception on diets that contained an equal number of calories but less protein (Riopelle and Hale, 1975). Gestation lengths varied by nearly 9 days under these conditions. Maternal nutrition also influences gestation length in golden hamsters, Mesocricetus auratus. In an experimental study, one group of female hamsters was maintained on a restricted diet, while another group of females was allowed to feed ad libitum. All females who were allowed to feed ad libitum gave birth after pregnancies of 16 days. One-third of the food-restricted females gave birth after pregnancies that lasted longer than 16 days, and some food-restricted females were pregnant for 19 days (Labov et al., 1986). Nutritional deprivation also lengthens gestation periods by 4-6 days in captive white-tailed deer (Verme, 1965) and by 4 days in domestic horses (Howell and Rollins, 1951). Habitat quality is also associated with gestation length among wild eland. Females living in poor habitats were pregnant approximately 14 days longer than females living in rich habitats.

In some species, however, nutritional deprivation during pregnancy appears to shorten pregnancy. When sheep and cattle are maintained on low planes of nutrition during pregnancy, their pregnancies are terminated several days earlier than those of females maintained on higher planes of nutrition (Alexander, 1956; Thomson and Thomson, 1949; Tudor, 1972). Sudden and severe weight loss and nutritional deprivation during pregnancy are known to be associated with reduction of gestation length in human females, but there is little information about the effects of moderate nutritional deprivation on gestation length (Hytten, 1980a, b; Lechtig et al., 1979; Ounsted and Scott, 1981; Smith, 1947).

In general, we know very little about the sources of variation in gestation length among females in free-ranging, unprovisioned populations. This is due at least in part to the fact that conception is difficult to detect in most species, and precise measurements of gestation length are therefore difficult to obtain. Baboons (Papio spp.) provide an important exception to this general rule; the reproductive condition of female baboons can be assessed from visual cues, and the date of conception can be estimated with considerable precision in the field. Moreover, baboons typically inhabit seasonal environments in which the availability and abundance of food resources 
change considerably. These conditions make it possible to examine sources of variation in gestation length. Here I report that variation in nutritional status during pregnancy may contribute to variation in gestation length among free-ranging yellow baboons (Papio cynocephalus) in Amboseli National Park, Kenya. In general, females that appeared to be most poorly nourished maintained the longest pregnancies.

\section{SUBJECTS AND METHODS}

\section{Study Population and Site}

Two groups of free-ranging and unprovisioned yellow baboons, Papio cynocephalus, were studied in Amboseli National Park, Kenya, from December 1982 through September 1983. Ecological conditions in the study area have been described in detail by Western (1972) and Western and van Praet (1973), and the baboon population has been censused intermittently since 1964 (Altmann, 1980; Hausfater, 1975; Altmann, and Altmann, 1970). Other studies have described the feeding behavior (Post, 1978, 1982; Post et al., 1980), the demography (Altmann et al., 1977, 1978, in press; Altmann, 1980), and various aspects of the social behavior of the Amboseli baboons (e.g., Stein, 1981; Altmann, 1980; Post et al., 1980; Walters, 1980; Hausfater, 1975). The majority of these studies has focused upon Alto's group, whose members have been habituated, individually recognized, and regularly observed since 1971 (Altmann, 1980). Similarly detailed observations of a second study group, Hook's group, were initiated in 1980. The members of these two groups were the subjects of the current study. At the beginning of the study period, Alto's group contained 52 individuals ( 8 adult males, 4 subadult males, 19 adult females, 10 juveniles males, 11 juvenile females), and Hook's group contained 39 individuals ( 7 adult males, 1 subadult male, 14 adult females, 8 juvenile males, and 9 juvenile females). By the end of the study period, membership in Alto's group and Hook's group had increased to 63 and 44 , respectively.

\section{Subjects}

All females that were pregnant during the study period became subjects of observations. Six females were pregnant when the study began, 12 females conceived and gave birth during the study period, and 7 conceived during the study and gave birth shortly after the study ended. Two more females that conceived during the study period miscarried during the first 
2 months of their pregnancies. One of these females and another female whose infant died 3 days after birth conceived again during the study period. Thus, 15 of the 19 adult females (79\%) in Alto's group and 10 of the 14 adult females $(71 \%)$ in Hook's group were observed during the course of the study (Table I). These females constituted a heterogeneous sample of the adult female population, varying in age, parity, dominance rank, and infant survivorship. The number of females that were simultaneously pregnant during the study ranged from 6 to 18 .

\section{Assessment of Female Reproductive Status}

The reproductive condition of female baboons can be assessed from visual cues. Nonlactating adult females experience regular estrous cycles ap-

Table I. Subjects of Focal Observations

\begin{tabular}{|c|c|c|c|c|c|c|c|}
\hline Female & Group & $\begin{array}{l}\text { Gestation } \\
\text { length } \\
\text { (days) }\end{array}$ & $\begin{array}{c}\text { Average } \\
\text { rank }\end{array}$ & Parity & $\begin{array}{l}\text { Infant } \\
\text { sex }\end{array}$ & $\begin{array}{l}\text { Infant } \\
\text { status }\end{array}$ & $\begin{array}{c}\text { Days } \\
\text { observed }\end{array}$ \\
\hline Safi & Alto's & 172 & 0.94 & 1 & $\mathbf{F}$ & LB & 7 \\
\hline Fanny & Alto's & 154 & 0.33 & 2 & $\mathbf{M}$ & NN & 10 \\
\hline Eno & Alto's & 172 & 0.06 & 1 & $\mathbf{M}$ & LB & 15 \\
\hline Slinky & Alto's & $179-180$ & 0.29 & 7 & $\mathbf{M}$ & LB & 19 \\
\hline Cete & Alto's & $175-176$ & 0.68 & 3 & $\mathbf{F}$ & L.B & 19 \\
\hline Dotty & Alto's & $175-176$ & 0.83 & 2 & $\mathbf{F}$ & LB & 19 \\
\hline Spot & Alto's & 184 & 1.00 & 5 & $\mathrm{~F}$ & NN & 26 \\
\hline Oreo & Alto's & 183 & 0.28 & 0 & $\mathbf{F}$ & LB & 25 \\
\hline Vee & Alto's & 209 & 0.55 & 4 & $\mathbf{F}$ & SB & 28 \\
\hline Handle & Alto's & 182 & 0.21 & 5 & $\mathbf{F}$ & LB & 20 \\
\hline Preg & Alto's & 172 & 0.32 & $7^{b}$ & $\mathbf{M}$ & LB & 17 \\
\hline Janet & Alto's & 172 & 0.00 & 2 & $M$ & LB & 17 \\
\hline Vixen & Alto's & 178 & 0.32 & 0 & $\mathbf{M}$ & LB & 19 \\
\hline Summer & Alto's & 172 & 0.78 & 1 & $\mathbf{F}$ & LB & 15 \\
\hline Nazu & Alto's & 181 & 0.63 & 2 & $\mathbf{F}$ & LB & 10 \\
\hline Fanny & Alto's & 177 & 0.15 & 3 & $\mathbf{F}$ & LB & 10 \\
\hline Nubbin & Hook's & 164 & 0.00 & $4^{b}$ & $\mathrm{~F}$ & LB & 14 \\
\hline Lamu & Hook's & $172-174$ & 0.36 & 0 & $\mathbf{F}$ & LB & 19 \\
\hline Pindua & Hook's & 178 & 1.00 & $5^{b}$ & $\mathbf{M}$ & LB & 21 \\
\hline Neena & Hook's & 173 & 0.68 & 1 & $\mathbf{F}$ & LB & 18 \\
\hline Lista & Hook's & 48 & 0.85 & $5^{b}$ & $?$ & AB & 4 \\
\hline Moja & Hook's & 173 & 0.17 & 2 & $\mathbf{M}$ & LB & 16 \\
\hline Kupima & Hook's & 56 & 0.50 & 0 & $?$ & $A B$ & 4 \\
\hline Lista & Hook's & 180 & 0.83 & $6^{b}$ & F & LB & 15 \\
\hline Penny & Hook's & 172 & 0.25 & 1 & F & LB & 14 \\
\hline Willy & Hook's & $174-175$ & 0.92 & 1 & $\mathbf{F}$ & LB & 11 \\
\hline Kupita & Hook's & 177 & 0.58 & $4^{b}$ & $\mathbf{F}$ & LB & 6 \\
\hline
\end{tabular}

${ }^{\mathrm{LBB}}$, survived first 6 months of life; NN, died within 1 week of birth; SB, died at birth; AB, fetus aborted before term.

${ }^{b}$ Parity may be underestimated for females that were multiparous adults when the groups were habituated. 
proximately 32 days in length (Hausfater, 1975). During the follicular phase of the cycle, the sex skin becomes swollen. Ovulation occurs shortly before the swelling reaches its maximal stage (Hendrickx and Kraemer 1971; Wildt et al., 1977; Shaikh et al., 1982). The sex skin shrinks rapidly during the luteal phase of the cycle. Long-term observations of cycling females in Alto's group have indicated that the estrous swelling deflates very quickly and that this portion of the estrous cycle is very uniform among females (Hausfater, 1975). It is therefore possible to identify the first day of detumescence with considerable accuracy when females are observed regularly. If females do not conceive, they menstruate approximately 2 weeks after the first day of detumescence of the sex skin, and the cycle is repeated. If females become pregnant, they do not menstruate or cycle again, and their black paracalossal skin begins to acquire a pinkish tinge. As pregnancy progresses, the change in the coloration of the paracalossal skin becomes more extensive and the color becomes brighter; the area round the eyes may also turn pink (Altmann, 1970). Gestation typically lasts 177 days (Altmann, 1980).

To monitor the reproductive condition of females, the size of the sexual swelling, presence of menstrual blood, and coloration of the paracalossal skin of all adult females were recorded on each occasion that the group was contacted. Alto's group was contacted on 201 days and Hook's group was contacted on 174 days during the 304-day study period. Thus, the reproductive condition of females in each group was recorded, on average, once every 2 days. Observations of females' reproductive status were made at similar intervals by other researchers before the present study began.

The group was also censused each time it was contacted. These frequent censuses provide precise information about the dates of parturition. In most cases, the exact day of birth is known because the group was censused on successive days. In some cases, the group was not contacted on successive days, but the first time the infant was seen its coat was still wet and matted, and the mother's perineum, hands, and feet were still bloody. Since the infant dries quickly and the mother cleans herself shortly after she gives birth, this was taken as evidence that parturition had occurred on the same day. In a few cases, the day of birth could be estimated only within a range of 2 or 3 days. In such cases, the minimum and maximum estimates of gestation length were averaged together to obtain the estimated gestation length.

Pregnancy was initially recognized when females failed to menstruate within the prescribed period after detumescence of the sex skin, or their sex skin did not begin to swell within a few days of the expected onset of the next cycle. For the purposes of this analysis, conception was assumed to have occurred on day $D-3,3$ days before the initial detumescence of the sex skin. This is the day on which Hendrickx and Kraemer (1969) reported that conception was most likely to occur in laboratory breeding experiments, although Wildt et al.(1977) found that most ovulations occur on the last day of max- 
imal turgescence or the first day of detumescence. In lieu of more consistent information about the timing of ovulation and conception in free-ranging animals, it is impossible to pinpoint the day of conception with certainty. While this may introduce small errors into estimates of the total length of gestation, it is unlikely to influence substantially the results of analyses of sources of variation in gestation length.

Pregnancy was confirmed when the upper portion of the paracalossal skin started to turn pink. Regular observations were initiated as soon as a female was suspected of being pregnant (mean, 17.8 days after conception; range, 3-27 days). Observations were terminated upon the delivery of an infant or the resumption of cycles, which indicated the occurrence of an early miscarriage.

\section{Behavioral Data Collection}

The results presented here are based mainly upon focal-animal observations (terms defined by Altmann, 1974) of adult females during their pregnancies. Three focal females were observed on each day that focal data were collected. Each female was observed for four 20-min periods distributed throughout the day. The first observation of the day began at $0740 \mathrm{hr}$, often before the baboons had descended from their sleeping trees, and the last observation of the day ended at $1700 \mathrm{hr}$, before the baboons entered their sleeping trees for the night. These four 20 -min samples collectively constituted a single "female day" in the analysis that follows. When a female became pregnant she was immediately inserted into the list of subjects, and when a female gave birth she was dropped from the list. An effort was made to ensure that individual females did not occupy the same position consistently in the daily observation order. The length of the interval between female days varied as the size of the sample of pregnant females changed (average interval, 7.6 days). The observation schedule was modified to accommodate occasional absences from the field and to include additional observations of females that were approaching parturition. The number of days on which each female was observed is listed in the last column in Table I.

During focal observations, the activities and social interactions involving the focal female were recorded on a continuous basis. Feeding was recorded when the animal manually or orally manipulated a food item. Chewing on food items that were wholly contained within the mouth was not scored as feeding, in accordance with conventions established by Shopland (in preparation) and S. Altmann (in preparation). Feeding rarely occurred at the same time as other activities and was, therefore, treated as a discrete activity state in the analysis that follows. 
The baboons were followed on foot and were usually observed from a distance of approximately $5 \mathrm{~m}$. Although observation conditions were generally very good, animals sometimes moved out of sight during observations. Moreover, problems with equipment or the proximity of lions, elephants, or buffalo sometimes delayed or interrupted observations. If an observation was interrupted for any reason, an entry was recorded to this effect. If the interruption lasted for more than half of the 20-min observation period, a new sample was begun as soon as the animal was found or conditions permitted observations to be conducted safely. If a sample could not be repeated or completed before the next sample was scheduled to begin, the sample was skipped. Out-of-sight time during completed samples accounts for appoximately $0.50 \%$ of all focal observation time $(N=547.6 \mathrm{hr})$. Approximately $1 \%$ of all scheduled samples were skipped.

In the field, data were typed directly onto a hand-held microcomputer (Radio Shack PC2) programmed in BASIC. The program was designed to accept alphanumeric data and to associate each datum with the current time. These data provide a continuous record of activities and interactions. At the end of each day's observations, the data were transferred onto cassette tape and were also printed and manually edited. Upon my return from the field, the data were transferred from cassette tape to a microcomputer for storage, editing, and analysis.

\section{Supplementary Information}

All demographic events (births, deaths, disappearances, immigrations, and emigrations), the reproductive condition of adult females, and injuries and illnesses to group members were recorded each time the group was contacted by any of the three investigators (A. Samuels, R. Mututua, and the author) then participating in the longitudinal baboon study. Agonistic interactions were recorded ad libitum in a standardized format by all investigators throughout the period of contact with the group.

Observations of dyadic agonistic interactions with clearly decided outcomes were used to establish the dominance hiearchy among adult females. The methods that have been used to assess dominance among the Amboseli baboons have been described in detail by Hausfater (1975) and Walters (1980). Briefly, decided agonistic bouts are those in which one individual, the "loser," performs only submissive behaviors (e.g., grimace, tail up, lean aside, crouch) in response to aggressive (e.g., bite, hit, lunge) or neutral behaviors by the "winner." Interactions were entered in a square matrix, in which females were ordered so as to minimize the number of entries below the diagonal.

Normally, individuals are assigned ordinal dominance ranks that correspond to the number of individuals they dominate. In a group numbering 
$\boldsymbol{n}$ individuals, the highest-ranking individual is assigned rank 1 and the lowestranking individual is assigned rank $n$. Such measures are problematic when individuals from groups of different sizes are compared. Hence, dominance rank is expressed here as the percentage of females dominated (after Cheney et al., 1981). This measure is calculated as $(n-m) /(n-1)$, where $n$ is the total number of females in the group and $m$ equals the female's ordinal rank. One is subtracted from the denominator because the individual itself is excluded from the potential number of females dominated. Thus, in a group of size 10 , the second-ranking individual dominates $89 \%$ of the other females in her group $[(10-2) /(10-1)=0.89]$. The highest- and lowest-ranking females dominate 100 and $0 \%$ of the other females in the group, respectively.

\section{RESULTS}

\section{Gestation Length}

There was considerable variation among females in the length of the interval between conception and parturition. Although the mean pregnancy lasted 176.1 days $(N=25$ pregnancies, excluding the two aborted pregnancies), the gestation length ranged from 154 days to 209 days. These figures are consistent with longitudinal data from Amboseli which indicate that the median pregnancy lasts 177 days (Altmann, 1980). Two infants that were born on days 154 and 184 died within 3 days of birth, and a third infant, born after a 209-day gestation period, was stillborn. The 22 remaining infants, which were born after pregnancies of 164-183 days (mean $=175.3$ days; $N=22$ ), survived at least their first month of life. Gestation lengths of the 22 surviving infants spanned a 19-day range.

It is suggestive that the shortest and longest pregnancies were experienced by females whose infants died within the first few days of life, but the number of nonsurviving infants is too small to evaluate the relationship between gestation length and mortality statistically. It is clear, however, that infant mortality does not account for all of the variation in gestation length. The pregnancies of females that produced surviving infants also spanned a considerable range. In the analysis that follows, several factors that contribute to variation in gestation length are identified. In each portion of the analysis, two sets of results are presented. One set of results is drawn from a sample that is composed of pregnancies that resulted in both surviving and nonsurviving infants. The other set of results is drawn from a sample that is restricted to pregnancies that resulted in surviving infants. 


\section{Characteristics of the Mother and Fetus}

Among the 25 females that produced surviving and nonsurviving infants, there is no evidence that gestation length is related to the characteristics of mothers or their fetuses. Gestation length is uncorrelated with maternal dominance rank ( $r=0.2267, P=0.138, N=25$ pregnancies) or maternal parity ( $r=0.2355, P=0.129, N=25$ pregnancies). Group membership has no consistent impact upon gestation length in this sample $(t=1.14, P$ $=0.127, N=25$ pregnancies). Finally, females that gave birth to male and female infants were pregnant for similar amounts of time $(t=-1.53, P=$ $0.145, N=25$ pregnancies).

The same results are obtained when the analysis is restricted to the 22 females that produced surviving infants. Among these females, gestation length is unrelated to maternal rank $(r=0.2122, P=0.172, N=22$ pregnancies), maternal parity ( $r=0.1694, P=0.225, N=22$ pregnancies), group membership ( $t=1.27, P=0.221, N=22$ pregnancies), or infant sex ( $t$ $=-0.28, P=0.783, N=22$ pregnancies).

\section{Ecological Correlates of Gestation Length}

In Amboseli, the onset of seasonal rains dramatically increases the diversity and abundance of the baboons' food resources (Post et al., 1980). Rainfall also increases the availability of surface water, which baboons drink daily. These seasonal changes in environmental conditions affected the activity budgets of pregnant females. When recent rainfall (that is, the amount of rain that had fallen during the previous 30 days) had been greatest, pregnant females spent the smallest proportions of their time feeding $(r=-0.2787$, $P=0.0001, N=418$ female days). Similar patterns have also been documented for lactating females in Amboseli (Altmann, 1980).

To determine whether the results cited above accurately reflect changes in the behavior of individual females, the relationship between recent rainfall and the proportion of time devoted to feeding was calculated separately for each female that was observed throughout her pregnancy or at least during the final two-thirds of pregnancy. Fifteen females were each observed on an average of 20 different days (range, 15-28 days). Thirteen of these 15 pregnant females spent less time feeding as the amount of recent rainfall increased. This sample includes two females whose infants did not survive the first week of life. However, the results are unaffected by the exclusion of these two females. Eleven of the remaining 13 females, which produced surviving infants, spent less time feeding as the amount of recent rainfall increased. While not all of these individual correlations reach statistical significance $(7 / 15, P<0.05 ; 5 / 13, P<0.05)$, the uniformity in the direc- 


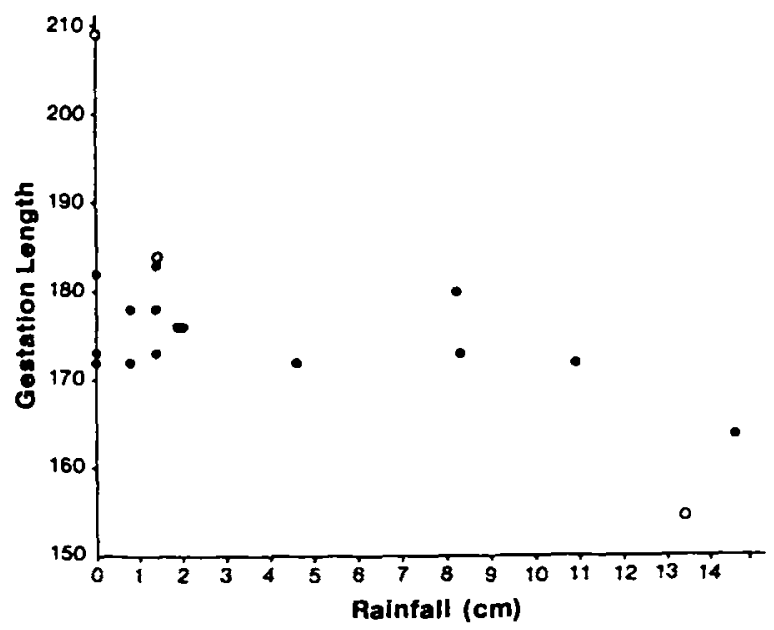

Fig. 1. Relationship between rainfall and gestation length. The cumulative amount of rainfall during the final third of pregnancy (days 118-177) is significantly negatively related to the total length of the gestation period (days). Open circles signify pregnancies that resulted in nonsurviving infants.

tion of the correlations suggests that feeding uniformly declined as the amount of recent rainfall increased.

The amount of recent rainfall is also related to gestation length. Females whose pregnancies ended during wet periods generally gave birth after shorter gestation periods than females whose pregnancies ended during drier periods. Rainfall during the final third of pregnancy (days 118-177) was negatively related to gestation length among 18 females for which information about rainfall during the final third of pregnancy was available $(r=-0.5709, P$ $=0.007, N=18$ pregnancies; Fig. 1). However, there was no correlation between the amount of rain that fell earlier in pregnancy and gestation length (days $1-59-r=0.0156, P=0.474, N=20$ pregnancies; days $60-118-r$ $=0.2528, P=0.141, N=20$ pregnancies; sample sizes vary because not all females were observed throughout their pregnancies). The amount of rainfall during the final third of pregnancy accounted for approximately $33 \%$ of the observed variation in gestation length.

The analysis above includes three focal females that gave birth to infants that did not survive the first week of life. These three females experienced the shortest (154 days) and the two longest pregnancies (184 and 209 days). Thus, there might be some suspicion that females whose pregnancies were terminated unsuccessfully were primarily responsible for the association between rainfall during pregnancy and gestation length. However, when these three pregnancies are excluded from the analysis, the results remain 
the same. Gestation length is negatively correlated with the amount of rainfall during the final third of pregnancy $(r=-0.5268, P=0.022, N=15$ pregnancies) but not with the amount of rain that fell earlier in pregnancy (days $1-59-r=0.0548, P=0.414, N=18$ pregnancies; days $60-118-r$ $=0.1727, P=0.254, N=17$ pregnancies; sample sizes vary because not all females were observed throughout their pregnancies).

\section{Behavioral Correlates of Gestation Length}

More detailed analysis suggests that the feeding behavior of pregnant females themselves also influenced the length of their pregnancies. Females spent significantly more time feeding as their pregnancies progressed $(r=$ $0.1322, P=0.003, N=418$ female days). However, since the amount of recent rainfall influences feeding behavior, variation in rainfall must be taken into account in assessing changes in feeding behavior over the course of pregnancy. It is especially important to do so here, because the amount of recent rainfall and fetal age are correlated. During the study period conceptions often followed rainy periods, and during this study period the amount of rain that fell in 1 month was positively correlated with the number of conceptions that occurred during the following month $(r=0.8542, P=0.0010$; Fig. 2). This meant that for many females, recent rainfall declined as their pregnancies progressed ( $r=-0.2836, P=0.0001, N=418$ female days).

Standard multiple regression procedures cannot be used to tease apart the effects of rainfall and gestational age because the two independent variables are correlated with one another (Wannacott and Wannacott, 1977). Hence, I chose a more conservative procedure for this analysis. A onedimensional linear regression was computed between recent rainfall and the proportion of time devoted to feeding. This yielded the following equation: $y=0.43-0.027 x$ (based upon a sample of 418 female days). The residual proportion of time devoted to each activity was then calculated. In effect, the regression equation is used here to provide a baseline prediction of the proportion of time that a pregnant female will spend feeding on a given day. The value of the residual indicates the direction and magnitude of the deviation from the expected value. A positive residual indicates that a female spent a greater proportion of her time feeding than expected on the basis of the amount of recent rainfall.

It should be noted that analyses based upon these residual values provide conservative estimates of the effects of gestational age upon maternal behavior, inasmuch as such analyses ignore all of the variation that can be explained by variation in rainfall, even though some of this variation may actually be due to variation in gestational age. Thus, analyses based upon the untransformed data provide an upper bound on the effects of gestational 

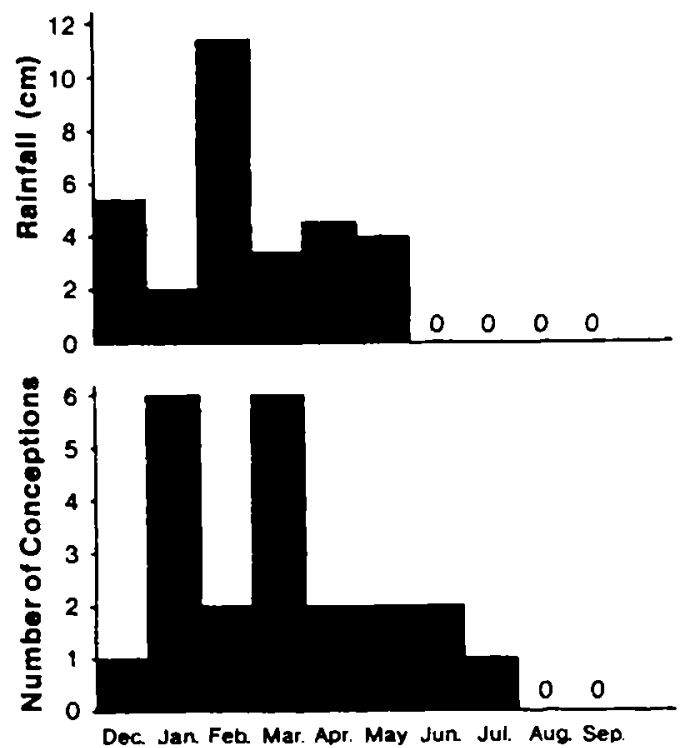

Fig. 2. Distribution of rainfall and conceptions. In the upper graph, the amount of rain that fell during each calendar month of the study is plotted. In the lower graph, the number of conceptions that occurred during each calendar month is plotted. The sample consists of 18 females that were observed during the final third of their pregnancies. The amount of rainfall in I month is significantly positively correlated with the number of conceptions that occurred during the following month.

age upon maternal behavior, while analyses based upon the residuals from the regression between recent rainfall and the proportion of time spent feeding set a lower bound on the effects of gestational age upon behavior. In short, the results cited below can only underestimate the strength of the relationship between gestational age and maternal behavior.

There was a nonsignificant increase in the residual proportion of time that females spent feeding as their pregnancies progressed $(r=0.0552, P$ $=0.1314, N=418$ female days). The weakness of this correlation suggests that gestational age had little impact upon maternal behavior or that not all females responded in the same way as their fetuses matured. Analysis of changes in behavior among individual females over the course of their pregnancies provides support for the latter hypothesis. To compare the feeding behavior of different females over the course of their pregnancies, the regression between gestational age and the residual proportion of time spent feeding during pregnancy was computed separately for individual 
females. The slopes of these regression equations signify the magnitude and direction of changes in the residual proportion of time spent feeding during pregnancy. A positive slope indicates that a given female spent progressively more time feeding as her pregnancy progressed, and a negative siope indicates the opposite trend. The sample consists of 15 females that were observed from conception to parturition, or during the final two-thirds of pregnancy, and includes two females whose infants died within the first week of life.

Ten of these 15 females devoted progressively more time than expected to feeding as their pregnancies progressed; the remaining five females spent progressively less time feeding as their fetuses matured.

These differences in behavior during pregnancy are noteworthy because variation in the pattern of change in maternal behavior during pregnancy is associated with variation in gestation length. Among females that gave birth to surviving and nonsurviving infants, the longest pregnancies were associated with the smallest increases in the residual proportions of time spent feeding during the first 177 days of pregnancy $(r=-0.6234, P=0.007$, $N=15$ pregnancies; Fig. 3 ). These patterns were more pronounced during the latter two-thirds of pregnancy (days 59-177: $r=-0.5391, P=0.019$, $N=15$ pregnancies) than during the first two-thirds of pregnancy (days

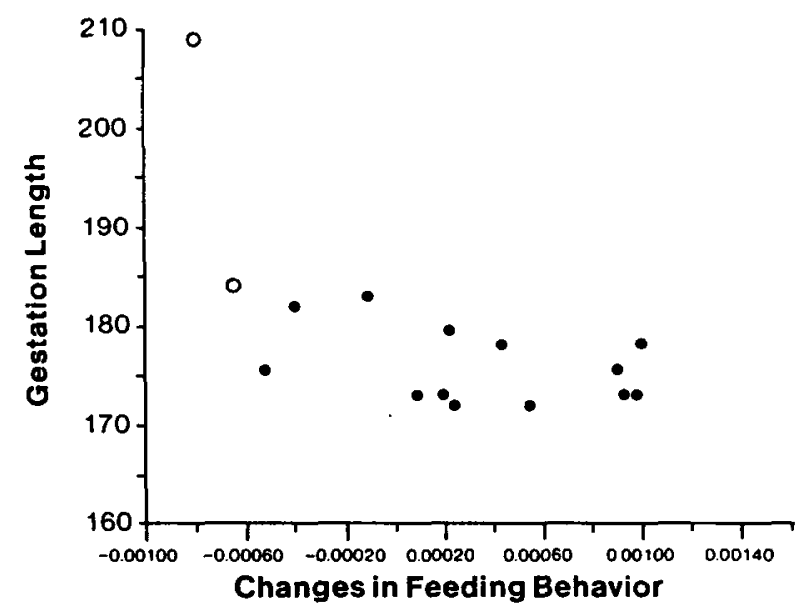

Fig. 3. Relationship between behavior and gestation length. The slope of the regression between the residual proportion of the time spent feeding and gestation day is plotted against gestation length (days). The sample consists of 15 females that were observed during the final two-thirds of their pregnancies or throughout their pregancies. Females whose feeding declined over the course of gestation were pregnant significantly longer than females whose feeding increased over the course of gestation. Open circles signify pregnancies that resulted in nonsurviving infants. 
1-118: $r=0.1891, P=0.242, N=16$ pregnancies; sample sizes vary because not all females were observed throughout their pregnancies).

When the sample is restricted to females that produce surviving infants, the significance of the correlation between gestation length and changes in feeding behavior over the course of pregnancy declines, although the correlation remains negative $(r=-0.3624, P<0.112, N=13$ pregnancies). The decline in the significance of this correlation suggests that this relationship may be an artifact of the fact the the two females that produced nonsurviving infants experienced the longest pregnancies and exhibited the most pronounced declines in feeding during the first 177 days of their pregnancies. However, there is some reason to doubt that the results can be dismissed so easily.

If the relationship between gestation length and changes in feeding behavior is due simply to the fact that females that produced nonsurviving infants behaved abnormally, there should be no consistent relationship between gestation length and changes in feeding behavior among the remaining females that gave birth to surviving infants after pregnancies that lasted longer than expected. Although the sample is very small, the relationship appears to be quite consistent among the five females that produced surviving infants after pregnancies that lasted 178-183 days $(r=-0.7740, P=$ $0.062, N=5$ pregnancies). Thus, it appears that this pattern is generally characteristic of all females that gave birth later than expected.

\section{Sources of Variation in Maternal Feeding Behavior}

While most females spent progressively more time feeding as their pregnancies progressed, some females responded quite differently. Approximately one-third of the pregnant females spent progressively less time feeding as their pregnancies progressed. A reduction of food intake over the course of pregnancy appears to be associated with an extension of gestation. Why do such differences occur among females? Four possible sources of variation in maternal feeding behavior during pregnancy are considered below.

\section{Maternal Dominance Rank}

Variation in feeding behavior during pregnancy is apparently not due to individual differences in access to resources during pregnancy. The agonistic dominance rank, a reliable correlate of priority of access to resources among these baboons (unpublished data), was not related to the pattern of changes in feeding behavior $(r=-0.1899, P=0.250, N=15$ pregnancies). Among females that gave birth to surviving infants, maternal rank is 
also uncorrelated with changes in feeding behavior during pregnancy ( $r=$ $0.0886, P=0.387, N=13$ pregnancies).

There is another reason to doubt that variation in access to resources was responsible for the correlation between changes in feeding behavior during pregnancy and gestation length. If this were the case, differences in the residual proportion of time spent feeding should have persisted until parturition. Instead, each of the six pregnant females (including two females that produced nonsurviving infants) observed after the expected day of birth, day 177, spent more time feeding between day 177 and the day she gave birth than she had during the previous 2 months (average residual proportion of time spent feeding: days 119-176-average $=-0.0519, N=54$ female days; after day 176 -average $=0.0454, N=26$ female days) (sign test: $P<0.050$ ).

\section{Fetal Sex}

Females that reduced their food intake over the course of their pregnancies were significantly more likely to be carrying female fetuses than male fetuses $(t=3.18, P=0.008, N=15$ pregnancies). Although the two females that exhibited the most extreme declines in feeding over the course of pregnancy produced nonsurviving female infants, this relationship remains significant when the analysis is restricted to females that produced surviving infants ( $t=2.29, P=0.049, N=13$ pregnancies). Thus, changes in maternal feeding behavior during pregnancy appear to be consistently associated with the sex of their fetuses.

\section{Group Membership}

Group membership was not related to changes in female feeding behavior during pregnancy ( $t=-1.51, P=0.174, N=15$ pregnancies). Among females that gave birth to surviving infants, similar results were obtained ( $t=-0.93, P=0.385, N=13$ pregnancies).

\section{Maternal Parity}

Maternal parity apparently does not contribute to variation in female feeding behavior during pregnancy among all females $(r=-0.1549, P=$ $0.291, N=15$ pregnancies) or among females who gave birth to surviving infants ( $r=0.0106, P=0.486, N=13$ pregnancies). Since the baboons were not handled, it is not known whether fetal growth rates, infant birth weights, or maternal weight gain varied in relation to gestation length or female feeding behavior. 


\section{DISCUSSION}

Among free-ranging pregnant female baboons in Amboseli, gestation lengths spanned a 55-day range. While the infants born after the shortest and the two longest pregnancies died within a few days of birth, gestation length also varied over 19 days among females that produced surviving infants. Several factors appeared to contribute to the variation in gestation length. As rainfall during the last third of pregnancy increased, gestation length declined. When variation in rainfall during pregnancy was held constant, another source of variation in gestation length emerged. Females that devoted progressively more time than expected to feeding during the course of their pregnancies were pregnant for shorter periods than females that devoted progressively less time than expected to feeding. Females that spent progressively less time feeding than expected were more likely to be carrying female fetuses than male fetuses. From these results, a number of questions arise. First, what is the cause of the relationship among rainfall, maternal feeding behavior, and gestation length? Second, what causes the feeding behavior of individual females to vary? Finally, what is the adaptive significance of variation in gestation length?

Evidence from several mammalian species indicates that maternal nutrition influences gestation length; when females are poorly nourished, gestation length is sometimes prolonged (Kiltie, 1982; Racey, 1981; Clegg, 1959). Both variation in the amount of rainfall and changes in feeding behavior during pregnancy are likely to have influenced the nutritional status of pregnant females in Amboseli.

Females whose pregnancies ended during the wet season in Amboseli might have been better nourished than females whose pregnancies ended during drier periods. Rain increases the diversity and abundance of foods available to the baboons (Post, 1978). Foods consumed during the wet season differed from those consumed during the dry season: corms and seeds were the staples of the dry season, while green grass blades, young leaves, and flowers became important components of the diet during the wet season (Silk, in preparation). Corms and seeds are considerably more difficult and timeconsuming to process than grass blades, leaves, and flowers (Altmann, 1980). It is evidently the ready availability of easily processed foods during the wet season that permits baboons to spend less time feeding during the wet season than during the dry season. For these reasons it seems likely that rainfall during the final third of pregnancy enhanced females' nutritional status.

Females that spent progressively more time feeding than expected over the course of gestation experienced shorter pregnancies than females that spent progressively less time feeding than expected as pregnancy progressed. These changes in feeding behavior were independent of changes in the amount 
of recent rainfall. There is little evidence that feeding rates or diet vary systematically among adult females (Post et al., 1982; Silk, in preparation). If all females had similar rates of food intake and similar diets, differences in the residual proportion of time spent feeding are likely to provide reasonable estimates of relative differences in food intake. Thus, it seems likely that pregnant females that spent progressively more time feeding than expected consumed more food and were better nourished than other pregnant females.

Taken together, these data support the hypothesis that females that gave. birth earlier than expected were better nourished than females that gave birth later than expected. Why is pregnancy extended when females are poorly nourished? Maternal nutrition infuences the rate of fetal development (Widdowson, 1981), and gestation length may somehow be adjusted to compensate for such differences in fetal development (Riopelle, 1982). It is also possible that there are individual differences in rates of fetal development and that it is these developmental differences that shape changes in maternal feeding behavior. These two hypotheses cannot be distinguished with the data at hand. However, in either case, gestation length should fluctuate in relation to infant development. Therefore, we might predict that infants born after long and short pregnancies should have similar birth weights and a similar developmental status. Riopelle and his colleagues (1975) have found that birth weight and other measures of infant development do not vary with gestation length among macaque infants born to females maintained on highand low-quality diets during pregnancy.

Differences in female feeding behavior during pregnancy account for a substantial fraction of variation in gestation length, but it is not clear why the behavior of individual pregnant females differed. Variation in changes in feeding behavior are not consistently associated with variation in maternal rank, maternal parity, or group membership. However, females carrying male fetuses experienced significantly greater increases in the residual proportion of time spent feeding than did females carrying female fetuses. These differences in feeding behavior may be due to the fact that females carrying male infants incur a heavier metabolic burden. Cercopithecine males typically weigh more at birth than females (Sackett et al., 1975; Riopelle and Shell, 1978; DiGiacomo et al., 1978).

Finally, it is important to consider the adaptive significance of sources of variation in gestation length. While extreme deviations from the mean gestation length appear to be deleterious, more moderate variations in gestation length have little observable impact upon infant survival. This may be taken as evidence that variation in gestation length is of little consequence. By the same token, one might argue that factors that contribute to variation in gestation length are also of little biological significance. This view is sup- 
ported to some extent by the clinical literature on human pregnancy. Maternal nutritional condition during pregnancy is correlated with infant birth weight, and infant birth weight is correlated with survival, but there is considerable latitude in these relationships (Hytten, 1980a, b). Perhaps as a result, there is little evidence that moderate nutritional deficits influence fetal development, infant birth weights, or mortality.

However, I suggest that neither the logic nor the data in support of this argument are compelling. Factors that cause gestation length to vary may be biologically significant, even though there is no correlation between gestation length and infant survival. Suppose, for example, that there is a set of physiological mechanisms that function to prolong gestation when the festus grows more slowly than expected. Since birth weight is correlated with infant survival (Hytten, 1980a, b), extension of the gestation period may increase the probability that an infant will survive. Similarly, if fetal growth is accelerated, and infants reach an optimal birth weight earlier than expected, there may be little risk associated with terminating pregnancy somewhat earlier than the median parturition date. When environmental conditions and maternal nutritional status vary within or between pregnancies, physiological mechanisms that provide some flexibility in gestation length may increase the reproductive success of mammalian females. Although there is little evidence that variation in gestation length influences infant survival, mechanisms that contribute to variation in gestation length may nonetheless be adaptive.

Although this hypothesis may be plausible, we cannot yet assess the adaptive significance of factors that contribute to variation in gestation length among baboons or other mammalian species. These results provide preliminary evidence that suggests that variation in maternal nutritional status is related to variation in gestation length among free-ranging baboons. More data from this site and from other baboon populations are clearly needed to substantiate these results. With such data, we may begin to understand the factors that contribute to variation in the length of mammalian pregnancies.

\section{ACKNOWLEDGMENTS}

I would like to than the Ministry of Tourism and Wildlife of the Republic of Kenya and the officials of Amboseli National Park for allowing me to conduct research in Amboseli National Park, and Dr. Jim Else and Ms. Mary Butayo of the Institute for Primate Research for their assistance with logistical details. I am grateful to Drs. S. Altmann, J. Altmann, and G. Hausfater for permitting me to participate in the study of the Amboseli baboons; my colleagues in the field, A. Samuels and R. Mututua, whose com- 
pany and help made my work much easier; R. Boyd for his support of this research; and several reviewers whose comments greatly improved the manuscript. The project was funded in part by NIMH National Research Service Award Fellowship 1-F32-MH-08670-01 and by NSF Research Grant BSR 82-19127.

\section{REFERENCES}

Alexander, G. (1956). Influence of nutrition upon duration of gestation in sheep. Nature (London) 178: 1058-1059.

Altmann, J. (1974). Observational study of behavior: Sampling methods. Behoviour 44: 227-267.

Altmann, J. (1980). Baboon Mothers and Infants, Harvard University Press, Cambridge, Mass.

Altmann, J., Altmann, S. A., Hausfater, G., and McCuskey, S. A. (1977). Life history of yellow baboons: Physical development, reproductive parameters, and infant mortality. Primates 18: 315-329.

Altmann, J., Altmann, S. A., and Hausfater, G. (1978). Primate infant's effects on mother's future reproduction. Science 201: 1028-1029.

Altmann, J., Altmann, S. A., and Hausfater, G. (in press). Determinants of reproductive success in savannah baboons (Papio cynocephalus). In Clutton-Brock, T. H. (ed.), Reproductive Success, University of Chicago Press, Chicago.

Altmann, S. A. (1970). The pregnancy sign in savannah baboons. Lab. Anim. Dig. 6: 7-10.

Altmann, S. A., and Altmann, J. (1970). Baboon Ecology, University of Chicago Press, Chicago.

Cheney, D. L., Lee, P. C., and Seyfarth, R. M. (1981). Behavioral correlates of non-random mortality among free-ranging female vervet monkeys. Behov. Ecol. Sociobiol. 9: 153-161.

Clegg, M. T. (1959). Factors affecting gestation length and parturition. In Cole, H. H., and Cupps, P. T. (eds.), Reproduction in Domestic Animals, Academic Press, New York, Vol. 1, pp. 509-538.

DiGiacomo, R. F., Shaughnessy, P. W., and Tomlin, S. J. (1978). Fetal-placental weight relationships in the rhesus (Macaca mulatta). Biol. Reprod. 18: 749-753.

Hausfater, G. (1975). Dominance and reproduction in baboons (Papio cynocephalus). Contrib. Primatol. 7: 1-150.

Hendrickx, A. G., and Kraemer, D. C. (1971). Reproductive Embryology of the Baboon, University of Chicago Press, Chicago.

Howell, C. E., and Rollins, W. C. (1951). Environmental sources of variation in the gestation length of the horse. J. Anim. Sci. 10: 789-796.

Hytten, F. E. (1980a). Nutrition. In Hytten, F., and Chamberlain, G. (eds.), Clinical Physiology in Obstetrics, Blackwell Scientific, Oxford, pp. 163-192.

Hytten, F. E. (1980). Weight gain in pregnancy. In Hytten, F., and Chamberlain, G. (eds.), Clinical Physiology in Obstetrics, Blackwell Scientific, Oxford, pp. 193-223.

Kiltie, R. A. (1982). Intraspecific variation in the mammalian gestation period. J. Mammal. 63: $646-652$.

Labov, J. B., Huck, U. W., Vaswani, P., and Lisk, R. D. (1986). Sex ratio manipulation and decreased growth of male offspring of undernourished golden hamsters. Behav. Ecol. Sociobiol. 18: 241-249.

Lechtig, A., Delgado, H., Martorell, R., Yarbrough, C., and Klein, R. E. (1979). Maternofetal nutrition. In Jellife, D. B., and Jelliffe, E. F. P. (eds.), Plenum, New York, pp. 79-127.

Ounsted, M., and Scott, A. (1981). Associations between maternal weight, height, weight-forheight, weight-gain, and birth weight. In Dobbing, J. (ed.), Nutrition in PregnancyEating for Two? Academic Press, New York, pp. 113-123.

Post, D. G. (1978). Feeding and Ranging Behavior of the Yellow Baboon, Ph.D. dissertation, Yale University, New Haven, Conn.

Post, D. G. (1982). Feeding behavior of yellow baboons (Papio cynocephalus) in the Amboseli National Park, Kenya. Int. J. Primatol. 3: 403-430. 
Post, D. G., Hausfater, G., and McCuskey, S. A. (1980). Feeding behaviour of yellow baboons (Papio cynocephalus): Relationships to age, gender, and dominance rank. Folia primatol. 34: 170-195.

Racey, P. A. (1981). Environmental factors affecting gestation lengths in mammals. In Gilmore, D., and Cook, B. (eds.), Environmental Factors in Mammal Reproduction, University Park Press, Baltimore, pp. 197-213.

Riopelle, A. J. (1982). Protein deprivation and of fspring behavior. In Fizzgerald, H. E., Multins, J. A., and Gage, P. (eds.), Studies of Development in Nonhuman Primates: Vol. 3, Child Nurturance, Plenum, New York, pp. 3-24.

Riopelle, A. J., and Hale, P. A. (1975). Nutritional and environmental factors affecting gestation length in Rhesus monkeys. Am. J. clin. Nutr. 28: 1170-1176.

Riopelle, A. J., and Shell, W. F. (1978). Protein deprivation in primates. XI. Determinants of weight change during and after pregnancy. Am. J. clin. Nutr. 31: 394-400.

Riopelle, A. J., Hill, C. W., Li, S., Wolf, R. H., Seibold, H. R., and Smith, J. L. (1975). Protein deficiency in primates. IV. Pregnant rhesus monkey. Am. J. clin. Nutr. 28: 20-28.

Sackett, G. P., Holm, R. A., Davis, A. E., and Fahrenbruch, C. E. (1975). Prematurity and low birth weight in pigtail macaques: Incidence, prediction, and effects on infant development. In Proceedings from the Fifth Congress of the International Primatological Society, Japan Science Press, Tokyo, pp. 189-206.

Shaikh, A. A., Celaya, C. L., Gomex, I., and Shaikh, S. A. (1982). Temporal relationship of hormonal peaks to ovulation and sex skin deturgescence in the baboon. Primates 23: 444-452.

Smith, C. A. (1947). The effect of wartime starvation in Holland upon pregnancy and its product. Am. J. Obstet. Gynecol. 53: 599-606.

Stein, D. M. (1981). The Nature and Function of Social Interactions Between Infant and Adult Yellow Baboons (Popio cynocephalus), Ph.D. dissertation, University of Chicago, Chicago.

Thomson, A. M., and Thomson, W. (1949). Lambing in relation to the diet of the pregnant ewe. Br. J. Nutr, 2: 290.

Tudor, G. (1972). The effect of pre- and post-natal nutrition on the growth of beef cattle. 1 . The effect of nutrition and parity of the dam on calf birth weight. Aust. J. agr. Res. 23: 389-395.

Verme, J. L. (1965). Reproductive studies on penned white-tailed deer. J. Wildl. Mgmt. 29: 74-79.

Walters, J. (1980). Interventions and the development of dominance relationships in female baboons. Folia primatol. 34: 61-89.

Western, D. (1972). The Structure, Dynamics, and Change of the Amboseli Ecosystem, Ph.D. dissertation, University of Nairobi.

Western, D., and van Praet, C. (1973). Cyclical changes in the habitat and climate of an east African ecosystem. Nature (London) 241: 104-106.

Widdowson, E. A. (1981). The role of nutrition in mammalian reproduction. In Gilmore, D., and Cook, B. (eds.), Environmental Factors in Mammal Reproduction, University Park Press, Baltimore, pp. 145-159.

Wildt, D. E., Doyle, L. L., Stone, S. C., and Harrison, R. M. (1977). Correlation of perineal swelling with serum ovarian hormone levels, vaginal cytology, and ovarian follicular development during the baboon reproductive cycle. Primates 18: 261-270. 